\title{
Editorial
}

\section{Blood Transfusion \& Rational use of blood}

Transfusion is the process of transfusing blood and its component, which may be between individuals of the same species or it may be retransfusion of collected blood into the same individual simultaneously or at a later date (Autologous transfusion). The decision to transfuse, like any other therapeutic decision should be based on the risks, benefits and alternative of treatment. Transfusion based solely on laboratory test- triggers in particular, are problematic. Consensus statements on the use of blood components such as those produced by the national blood transfusion policy and guide and clinical judgment.

Since transfusion is not without hazard so before administration we must determine the judgment and rational use of blood. The word 'WHAT' for any such procedure-

W- Whether blood transfusion required

H- How much required

A- Actual component required

T- Time duration of transfusion i.e rate of blood administration.

To determine 'WHAT' indications for transfusion must be known and the particular component required or suitable for the condition. Sometimes blood transfusion may be the only required for improvement of $\mathrm{Hb} \%$, necessary for preoperative or peroparative during surgery or any medical condition, which may reduce the morbidity and mortality of the patient. Emergency blood transfusion may be necessary due to hypovolemia in RTA, hemorrhage, bleeding disorder or any cause of active bleeding. Blood loss $30 \%$ or more is the definite indication of blood transfusion. In addition, $\mathrm{Hb} \%$ below normal or chronic anemia, due to chronic illness, cancer, chronic Gl tract bleeding \& blood diseases. Blood is not a single thing; but it is a liquid connective tissue composed of cells and plasma, cells are RBC, WBC \& platelets. Plasma contains soluble and non- soluble substances. The primary indication for transfusion of RBCs is to restore or maintain oxygen carrying capacity to meet tissue demands; transfusion to replace red cells destined for destruction in hemolytic disease of new born, thalassemia. Hematocrit value less $<30 \%$ on the hemoglobin concentration $<10 \mathrm{gm} \%$ is a parameter of blood transfusion.

Blood transfusion commonly practiced in human being are mainly two types:

(i). Homologous transfusion

(ii). Autologous transfusion

Homologous transfusion is the transfusion of compatible homologous (different individuals amongst the same species) blood of the same specific or compatible group. Autologous (Auto-self) transfusion is the retransfusion of collected blood simultaneously or at a later date into the donor himself/ herself.

Homologus blood transfusion is the sheet anchor for transfusion practice till recently; but since 1970, When the autologous transfusion was approved for practice in many countries like U.S.A, U.K etc. Autologus blood transfusion can be a safe blood transfusion practice \& prevent TTls standards of transfusion reaction. Autologus blood transfusion is gradually becoming popular and expected to play a significant role in future transfusion practice.

The commonly practiced mode of transfusion still now so the procedure normally adopted for transfusion of blood into the recipient is described vide intra. Whole blood must be $\mathrm{ABO}$ identical $\mathrm{RBC}$ conc must need identical \& compatible with $\mathrm{ABO}$ antibodies in the recipient's plasma, Rhesus blood grouping (Dc CEè) have 5 (five) antigens; but only D-antigen is detected during grouping. Others are not so common, but can causes hemolytic transfusion reaction for this reason cross match (compatibility) is essential with ICT (indirect comb's test) in three phase method. When identical ABO blood group is not available, then 2nd or 3rd option is there for active bleeding or lifesaving cases.

Allo antibodies to red cell antigens may be initially detected in any test that uses serum or plasma (e.g ABO test, Antibody detection test, cross match) or in evaluate prepared from red cells coated with alloantibody. Once an antibody is detected; its specificity should be determined and its clinical significance assessed. Because PTS (Post transfusion survival) of the cells depend on antibody amaount in the serum/ plasma. 
Some antibodies cause destruction of incompatible red cells within hours or even within few minutes. Other decrease the survival by only a few days. Selection of blood for transfusion depend on blood group antigen present in the RBC of the donor, Once an antibody has been identified, It is important to decide its clinical significance. These antibodies are clinically important, which reactive at $37^{\circ} \mathrm{C}$ Some option or choices are given below for alternative blood transfusion group.

\begin{tabular}{|l|l|l|l|l|}
\hline $\begin{array}{l}\text { Recipient } \\
\text { Blood group }\end{array}$ & first choice & $2^{\text {nd }}$ choice & $3^{\text {rd }}$ choice & $4^{\text {th }}$ choice \\
\hline AB & AB & A & B & O \\
\hline A & A & O & & \\
\hline B & B & O & & \\
\hline O & O & & & \\
\hline
\end{tabular}

Table: followed in AA BB text book, 15th Edition

So, specific ABO blood group is 1st choice; but for life saving or in critical emergency alternate choice is there. So, in active bleeding the option should be followed. In case of Rhesus grouping only ' $\mathrm{D}$ ' is very significant and can cause sever Haemolytic Transfusion Reaction (HTR), Others are not so Important; but can cause HTR \& HDN. In case of D negative donor blood should be given by $\mathrm{D}$ negative blood group. But $\mathrm{D}$ positive recipient person can accept $\mathrm{D}$ negative blood group and there will be no (Haemolytic Transfusion Reaction) HTR on (Haemolytic Disease of Newborn) HDN. Above all today is the day of digital day, So whole blood use should be restricted and we can say "Right thing to the Right person in right time" ie component therapy is better therapy and follow Principles of Clinical Transfusion Practice-

*(1) The patient with acute blood loss should receive effective resuscitation (intra venous replacement fluids, oxygen, etc.) immediately and the need for transfusion is to estimate later on.

*(2) The patient's hemoglobin value, although important should not be the sole deciding factor in a decision making of transfusion. This decision should be supported by the need to relieve clinical signs and symptoms and to prevent significant morbidity and mortality.
*(3) The clinicians should be aware of the risks of transfusion transmissible infection (TT1s) in the blood products that are suitable for the individual patient.

*(4) Transfusion should be prescribed only when the benefits to the patient are likely to outweigh the risks transfusion transmissible infections.

*(5) The clinician should record the reason for transfusion clearly.

*(6) A trained staff should monitor the transfused patient and respond immediately if any adverse effects occur.

The overall idea is to transfuse safe blood to the patient and for this safe blood transfusion the strategies are:-

1. Blood donated by healthy donor by careful selection of the donor.

2. Free from any infections that could be harmful to the patient.

3. Processed by reliable methods of testing component production, storage and transport.

4. Transfusion only may need and used for the patient's health and wellbeing.

The quality and safety of all blood and blood products must be assured through the process from the selection of blood donors to their administration to the patient. This requires as per 'WHO' blood safety initiative.

The blood transfusion and blood products should be advised only to treat a condition leading to significant morbidity or mortality that cannot be prevented or managed effectively by other means.

\section{Prof. Dr. Muhammad Shahidul Islam Professor \& HOD \\ Department of Transfusion Medicine $\mathrm{KYAMCH}$}

